\title{
Spectroscopic Measurement of Leaf Water Status
}

\author{
Alexander F. H. Goetz 1,2, Joseph W. Boardman 1 \\ ${ }^{1}$ Center for the Sudy of Earth from SpaceKCIRES \\ 2 Department of Geological Sciences, \\ University of Colorado, Boulder, Colorado 80309
}

\begin{abstract}
A leaf drying experiment was carried out in the laboratory in which simultaneous spectral reflectanoe in the $350-2450 \mathrm{~nm}$ region, and leaf weights, were measured at 10 second intervals over a 40 minute period. As the leaf water weight droppod from approximately 60 to $38 \%$, a nearlylinear rise in reflectance at all wavelengths beyond $1000 \mathrm{~nm}$ was observed. A principal components analysis of the time series of spoctra in the 2000-2500 nm wavelength region showed that over $99 \%$ of the variance in the spectra, that were individually scaled to have a sum equal to that of the mean spectrum and subsequently mean corrocted, was in the first component. This result shows that it is feasible to determine leaf water content remotely with an imaging spoctrometer independent of the surface irradiance effocts caused by topography.
\end{abstract}

\section{INTRODUCTION}

The remoce detection of plant water stress from drought has boen a major research goal for a number of years for crops [1. 2] and forests $[3,4]$. Of importance here is the relative water content (RWC) that is definod as the water volume of a leaf divided by the maximum water volume at full turgor [4]. The objective of this study was to develop an algorithm to determine leaf water content in the physiologically important range of values, independent of brightness associated with surface topography and taking into acoount the natural variability among vegetation types.

\section{LABORATORY METHOD}

The labocatory measurements consistod of acquiring reflectance spectra of an illuminated single large leaf, overlying a white Halon standard, positioned on a balanoe with $10^{-3} \mathrm{gm}$ digital readout precision. The fiberoptic-bundle, spectrometer input probe had a forooptic that restricted the view to a $5^{\circ}$ full angle and was pointed vertically at the leaf. The illumination consisted of two, $50 \mathrm{~W}$ quartz- halogen reflector lamps situated on opposite sides of the sample, approximately $45^{\circ}$ off normal. The measurement configuration is shown schematically in Fig. 1.

The lamps were positioncd at a distance of approximately 20 $\mathrm{cm}$ from the sample in order to dry the leaf to approximately $60 \%$ of its original weight in approximately 40 minutes. After the measurement cycle was completed, the leaves were further driod in an oven at $60^{\circ} \mathrm{C}$ overnight and re-weighod to obtain the dry weight. The reason that only one leaf was used in the experiment, rather than a stack of leaves that would more realistically represent the reflectance of a canopy, was that the drying rate could be controlled only for a single leaf. The spectrometer used was a FieldSpectMrFR (Analytical Spectral Devices, Boulder). The spoctrometer acquires a refloctance spoctrum spanning the wavelength range 350-2450 $\mathrm{nm}$ in 0.1 seconds.

\section{SPECTRAL MEASUREMENTS}

A data set for a leaf consisted of 240 spectra, each of which is made up of the average of 50 individual spectra, and time stamped so that for any given measurement spectrum, a leaf weight and water content were retrievable. Fig. 2 shows the spectrum of a Basswood (Tillia americana L.) leaf at the beginning of the measurement cycle. The reason for the high reflectance in the infrared plateau around $800 \mathrm{~nm}$ is that only one leaf is being measured, and the leaf is lying on a white Halon standard that reflects essentially all the transmitted light back through the leaf. In a canopy the maximum reflectance would be lower.

\section{NEAR INFRARED REGION RESPONSE}

The region beyond $1000 \mathrm{~nm}$ exhibits a steadily increasing reflectance as a function of time for all wavelengths. This can be explainod by the fact that water absorbs strongly at all wavelengths in this region.

The behavior of the reflectance at the absorption maxima for three water features at $1191 \mathrm{~nm}, 1444 \mathrm{~nm}, 1927 \mathrm{~nm}$ are shown in Fig. 3. The reflectances shown in Fig. 3 increase nearly linearly with decrease in water content of the leaf. However, for purposes of remote sensing, only the absorption feature at $1191 \mathrm{~nm}$ is available for determination of liquid water content, since the features at $1444 \mathrm{~nm}$ and $1927 \mathrm{~nm}$ are hidden by doep atmospheric water vapor absorption features. that are saturated in these regions.

The region 2000-2400 $\mathrm{nm}$ exhibits significant change in shape as drying occurs, as shown in Fig. 4. In particular, the features associated with cellulose and lignin appear as separate peaks in the dry spectrum and as a single peak in the initial spectrum in the drying sequence [5]. In order to better display the spoctral behavior with time, the spectra have been ananged in a throe-dimensional plot shown in Fig. 5. It is interesting to note that the strong features that appear at the end of the drying cycle, and are associated with the dry leaf spectra, do make their appearance throughout the drying cycle and, in a very subdued form, even in the first fresh leaf 
spectrum. This fact makes possible the determination of the chemical composition of fresh leaves by applying first and second difference lochniques to the spectra [5].

\section{DATA ANALYSIS}

As shown in Fig. 3, the change in leaf water status is evident and retrievable from the depth of the water absorption feature at $1191 \mathrm{~nm}$, but the change with water status is small, requiring very high signal-to-noise ratio in the sensor and an initial band depth, possibly for each species. Therefore, it is important to use an extended segment of the spectrum with a sufficient number of spectral bands to increase the apparent signal-to-noise ratio, and make use of the changing shape of the spectrum as the leaf dries. We propose a tochnique for spectroscopic measurement of leaf water status based on the diagnostic changes seen in the shape of the refloctance curves in the 2000 to $2400 \mathrm{~nm}$ spectral region. It stould be possible to use imaging spectrometry data in this infraned atmospheric window region to infer leaf water status.

The dimensionality and nature of the drying-inducod spectral changes in the 2000-2400 nm spectral region were examined with a principal components analysis. We resampled the 400 spectral channels covering this $400 \mathrm{~nm}$ range to 200 channels, recreating the $2 \mathrm{~nm}$ sampling interval of the instrument. The mean spectrum was subtracted from each spectrum, centering the data on the origin. Then the covariance matrix, eigenvalues and associated eigenvoctors were calculated. The overwhelming dominanoe of the first eigenvalue indicates a nearly linear progression from the first spectrum to the last. The path followed by the spectra of the drying leaf in spectral-space is essentially linear. Fig. 6 shows the first eigenvector which points in the direction of spoctral change of the series of drying-leaf spectra.

Fig. 7 illustrates the projection of each of the 240 spectra, from wettest to driest, onto the first eigenvector. There is a nearly linear progression of the first eigenvector projections of the spectra. The slope of this line is many times greater than those shown in Fig. 3, indicating the substantial increase in sensitivity that results from a joint analysis of many spectral bands.

\section{SUMMARY AND CONCLUSIONS}

The availability of a new, rapid-reading spectrometer has made it possible to develop a high time-resolution image of the spectral refloctance response of a leaf to drying. The simultaneous recording of the leaf weight made it possible to assess the relationship betwoen spectral reflectance and leaf water content quantitatively. At wavelengths longer than 1.0 $\mu \mathrm{m}$, spectral reflectances increase uniformly as the water content is reduoed by drying. The results of a principal components analysis show that, when the leaf is dried, the $2000-2400 \mathrm{~nm}$ spectral region exhibits the greatest spectral change, independent of albedo change. This result leads to the conclusion that a quantitative method can be developed to measure leaf water content remotely by imaging spectrometry. A muluispectral scanner such as Landsal with one band in this spoctral region, or even a seanner with several bands would not provide sufficient data for this method. The level of procision can be expocted to be on the order of $\pm 1 \%$ with a sensor such as AVIRIS. Further study will be required $t o$ assess the level of accuracy that can be expectod under the conditions of remote sensing using the proposed principal components method.

\section{ACKNOWLEDGMENTS}

The authors wish to thank Bruce Kindel of CSES for help in data acquisition, as well as Brian Curtiss of Analytical Spectral Devices Inc. for the loan of the FieldSpectm.FR. This research was supported by a contract with Texas Instruments Inc. and contract NAS5-31711 with the NASA Goddard Spaceflight Center.

\section{REFERENCES}

[1] Bawer, M.E. C.S.T. Daughtry, LL Bichl. E.T. Kenemasu. and F.G. Hall, Field spectroscopy of agriculaural crops. IEEE Trans. Geosci. Remoce Sens., GE-24, 65-75. 1986.

[2] Hunl, E.R., Jr, B.N. Rock, and P.S. Nobel, Measurement of leaf relative water content by infrarod reflectance. Remote Sens. Env., 22. 429-435, 1987.

[3] Hunt, E.R., Jr., and B.N. Rock, Detoction of changes in leaf water content using nerr-and middle-infrared refloctances. Remole Sens. Env., 30, 43-54. 1989.

[4] Elvidge, C.D. Visible and near infrared refloctance characteristics of dy plant materials, Ins. J. Remote Sens., 11. 1775-1795, 1990.

[5] Martin, ME. and J.D. Aber. Determining the chemical composition of fresh leaves using near-infrared spectra. submitted, 1994.

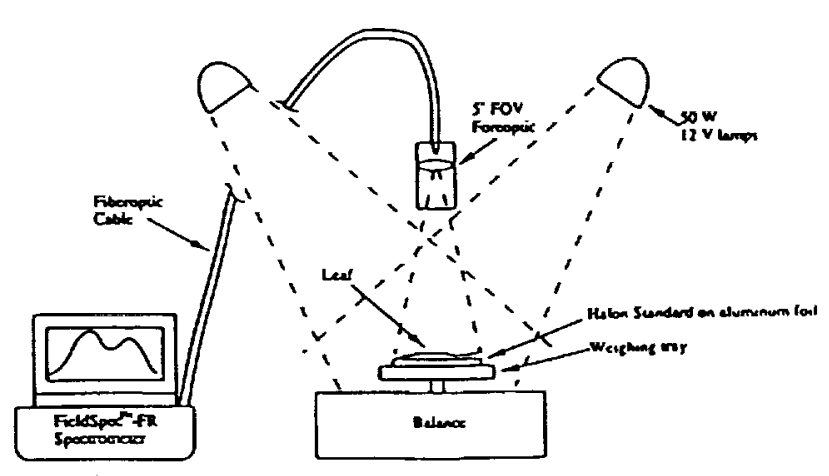

Figure 1. Schematic diagram of the spectral and mass measurements. 
